\title{
Empirical Research of Motivation on Knowledge Contribution Behavior: A Perspective on Chinese Original Users from Education Multimedia Platform
}

\author{
Jing Du, Liyong Wan, Jingjing Xu, and Ronghuai Huang
}

\begin{abstract}
The existence of original UGC of education makes learners can get learning resources through diverse channels, this will change the way of learning and the users' active participation guarantee the generation of original UGC of education. This research is based on motivation theory, social exchange theory and self-efficacy theory, putting forward an original generating motivation hypothesis model on original UGC of education from two dimensions, individual and society, extracting 6 factors and 7 theoretical hypotheses for motivation study. The object of this empirical research is the creator of original UGC of education and verify 7 hypotheses with structural equation model. Finding that lifelong learning have a positive impact on users' enthusiasm to generate content.
\end{abstract}

Index Terms-User generated content, open learning resource, motivation, structural equation modeling.

\section{INTRODUCTION}

Education today face a range of challenges, such like its role in society, the functions of universities [1], and increasing diversity and quantity of the student [2], User Generated Content (UGC) may change the current situation. User-generated content (UGC) exists in social media platforms specially, is plays key role in online ecosystem [3]. As for the fast development of Internet and interactive social media, more and more people are likely to share the content they create to others online. There are three main characteristics for UGC [4]. First, consumers are now the producers. The user in the Internet confined to passive consumption in the past while they have an active role under the effect of social media platform [5]. Second, production occur without immediate profit motivation. An active consumer is not directed by a short term financial goal which also means a majority of user generated contents are not used to generate immediate profits. Third, UGC is produced by social media platform. The person who willing to generate content is uncertain, so we need to distinguish the person who have a motivation in generating contents [6]. In china, the platform to produce UGC ranging from Wikipedia, 360DOC to Baidu Library and so on. In the year to December, 2016,

Manuscript received June 10, 2017; revised November 25, 2017.

Jing Du and Jingjing $\mathrm{Xu}$ are with the Smart Learning Institute of Beijing Normal University, Beijing, China (e-mail: dujing@mail.bnu.edu.cn, xujingjing@mail.bnu.edu.cn).

Liyong Wan is with the School of Education, South-Central University For Nationalities, China (e-mail: liyongwan2010@126.com).

Ronghuai Huang was with Beijing Normal University, Beijing, China. He is now with the Smart Learning Institute of Beijing Normal University, Beijing, China (e-mail: huangrh@mail.bnu.edu.cn). there exists 668 million Internet users in China [7], the vast number of users is the foundation for the development of the digital resources online. However, according to online community the 90-9-1 law proposed by Nielsen [8], only $1 \%$ produces the most part of content on multimedia platform. So we need to take some actions based on research to show how to motivate the user contributing their knowledge.

User-generated content (UGC) has becoming much more popular with the hselp of Web 2.0 technologies. Technology is an essential and required element learning and teaching. UGC is a new mechanism to share content online and give opportunities to teachers and students to gain knowledge from more ways [9]. Which means students and teachers can share, collaborate and acquire resources in the process of learning and teachers can adopt the content to classroom. The knowledge creation metaphor indicates that learning is a process of developing collaborative-shared objects and artefact [10]. That is to say, UGC can be considered as a typical co-creating knowledge objects on the website. So we can consider that UGC may have the potential to improve the situation of teaching in college and possibly provide more materials for students and teachers. Researchers have investigated the possibility of integrating UGC into teaching and learning in recent years because of the features UGC had, such as free to access. Wheeler et al. study about whether it is works to promote collaborative learning of college students by using wiki systems, a co-editing system. Furthermore, co-editing Wikipedia may transfer knowledge [11], crowdsourcing may provide the opportunity to make use of an innovative idea from the masses [12], and the question-answer communities may help people solve their problems [13].

However, continually creating content without a core content strategy leads to duplication, inconsistency, inaccuracy and disconnected pathways [14]. Some user will copy content from other users, which lead to a phenomenon of plagiarism. The construction of learning resources online has a close relationship with the development of UGC on education and the contribution of the user. There exists plenty of repetitive resources online hampering the prosperous development of the UGC in education. And original content and user creation enthusiasm is the insurance for well development of resources online. However, few papers focus on the original user generated content's perspective. One purpose of this study was to focus on original user to study about why they glad to contribute their knowledge on the basis of motivation theory, social exchange theory as well as self-efficacy theory. Another purpose was 
to give some advices based on this study about how to motivate the user online share their knowledge.

\section{LITERATURE REVIEW}

Different researchers have different opinions on the motivation of user generated content. Some researchers hold the view that the reason why people want to generate content has a close relation to helping others and wanting desire. Motivation theory has widely been used to explain individual's behavior of using information technology in previous research [15]. Motivation is unobservable. The thing we can do to observe motivation is from behavior [16]. Deci classified the motivations into extrinsic motivation and intrinsic motivation. Extrinsic motivation mentioned about committing an action as for its perceived helpfulness in achieving value (e.g., the performance of improvement) [17], while intrinsic motivation refers to committing an action as for interest in the action itself, rather than external reinforcement [18]. Kim et al. pointed out that perceived benefit affects the individual's attitude on using technology. Motivation theory plays a great role in the field of Management and Systems Science, Sociology [19]. Baumeister thought deeply about the construction of a general theory of motivation and offers ideas about what such a theory might require. [20] One assumption is that the expression "motivation" refers to wanting (desire). Therefore, the desire to acquire information online is one of the motivation to use social media platform.

Some other researchers think the reason why person on multimedia platform has a strong desire to generate content relate to social factors. One of the most influential conceptual paradigms in descripting organizational behavior is Social exchange theory. [21] Social exchange theory refers to in interdependent relationships, transactions between parties beget a norm of reciprocity and, possibly, quid pro quo reciprocity [22]. The reciprocity norm [23] specifies that favorable treatment received by one party obligates him/her to provide favorable treatment in return. A study on the basis of needs hierarchy from Maslow, the cost includes cognitive and executional costs demonstrates that a sense of self-worth, social support, and improving reputation positively impact both general and specific knowledge sharing. [24] Furthermore, social exchange theory has the character on emotional evaluation (i.e., satisfaction on the quality of process and outcome) and rational evaluation (i.e., learning).

The social exchange describes the motivation form social factors, the factors related to individual such as self-efficacy will also influence the person's generate behavior. Self-efficacy is defined by Bandura as one's ability to judge and deduce individual's behavior over completing one thing. That is to say, self-efficacy is a conviction about what a person can do and how well he or she can do it [25], [26]. It determines how peoples' perceived goals, values, and behavior influenced by environmental opportunities and impediments [27]. Thus social media have the potential to enhance students' self-efficacy in learning and can support students to make great effort in developing their learning [28]. Hong hold the view that self-efficacy and learning interest was positively correlated to learning satisfaction. [29] Thus, we may expect users' self-efficacy has a close relationship with contribution and learning behavior. However, self-efficacy cannot have effect on desirable behavior alone, the individual behavioral capability (knowledge and/or skill) is indispensable to perform the specific act [30]. Therefore, the self-efficacy, such like interest in helping others, is one of the motivation to use social media platform. As a result, in this article, we will take a person's knowledge level into consideration.

User-generated content (UGC) has received wide attention in last decade. Knowledge embedded UGC has been emphasized as a valuable Internet asset [31], [32]. Currently, the primary stream on UGC research focus on motivation. Poch and Martin examine the effect for altruism (individual difference-intrinsic motivation), social benefits (extrinsic reward), and economic incentives (extrinsic reward) on intentions to create UGC, showing that extrinsic rewards (economic incentives) result in more positive intentions to create UGC than intrinsic motivations and an effect of altruism is also obviously revealing that high altruism consumers are more likely to create positive UGC. [33] Knoll and Proksch surveys 181 social media users on motivation, personality and attitude toward advertising in general, showing that quantity on knowledge contributed on social media platform can be enhanced greatly with the influence of rewards in reputation systems and learning is proved to be a crucial motivational factor in this context. [34] However, enjoy helping is weakly related with knowledge contribution quality [35].

Additionally, self-presentation, self-promotion, and creativity were noted, based on her analysis of Polish blogs. Thus, we can conclude that, the study about motivations to generate content is rich. It may be concluded that the motivation to generate content may include reputation system, individual factor and social benefits.

\section{RESEARCH MODEL AND HYPOTHESIS}

As describe in above, we set hypothesis that 89 type of motivation (lifelong learning, user response, self-regulatory, enjoy helping, self-efficacy, interest and curiosity, social identity and altruism) the research model (show in Fig. 1) is showed.

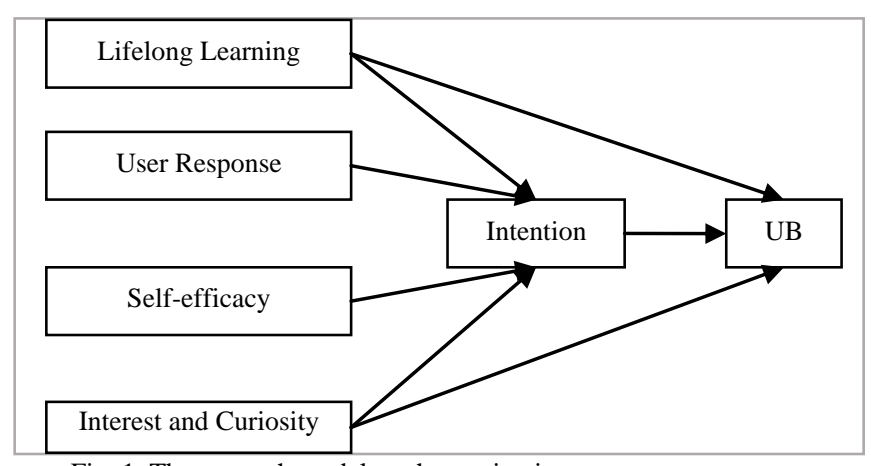

Fig. 1. The research model on the motivation to generate content.

\section{A. Lifelong Learning}

Answering others' questions involves certain level of information processing [36], since it needs contributors give 
a solution after deeply thinking. when contributing, participants can learn from the process of explaining their idea to others [37]. Learning is a kind of internalized extrinsic motivation since it does not stem from the internal enjoyment of the activity. The lifelong learning motivation may have a positive impact on knowledge contribution. We also suppose that lifelong learning may have a positive effect on user-generated behavior and self-efficacy.

H1. Lifelong learning will have a positive effect on behavioral intention.

\section{B. User Response}

Studies in psychology show that higher performance can be enhanced by the positive feedback of individuals' competence [38]. The speed of user response will affect the efficiency of the communication between the users, when a user uploads a content, and other user does not respond, the user doesn't want to continue to generate the next time. So we think user response may have an effect on time devotion and user generated content.

H2. User response will have a positive effect on behavioral intention.

\section{Self-efficacy}

As self-efficacy beliefs are task-specific, a person with high self-efficacy will tend to exhibit certain positive personal qualities such as persistence, strategic planning and high achievement. Tower has ever proved that social media platforms can enhance students' self-efficacy in learning as for social media platform can support students to develop their learning. Ability. [39] So we infer that self-efficacy will also affect user's generated behavior.

H3. Self-efficacy will have a positive effect on behavioral intention.

\section{Interest and Curiosity}

It is innate interest when going after a goal or working on an activity [40]. Curiosity is one of the intrinsic motivation of individual learning and knowledge. Einstein had ever said that his success is because of is that he has a fever for the curiosity of reason.

H4. Interest and curiosity will have a positive effect on behavioral intention.

\section{E. Self-regulatory}

Self-regulatory is a complex process that modulates one's behavior in a given situation. If a user can have high self-regulation, he or she may not intend to copy the contents of the rest of the author. There is a close relation between emotion self-regulation and symptoms of depression, anxiety, eating pathology, and behavior [41].

H5. Self-regulatory will have a positive effect on behavioral intention.

\section{F. Behavioral Intention}

H6. Behavioral intention will have a positive effect on user-generated behavior.

Existing work has mostly considered the aspects of user and system characteristics using TAM. Web 2.0 acts as an interactive platform for users sharing their views and opinions.

\section{Methodology}

\section{A. Data Collection}

The data for this study was collected by a questionnaire provided to individuals who contribute UGC on the platform of 360DOC, Youku Video, 51ASPX, OSC (Open source China) and Douban. According to the principle of convenience sampling, 20 participants were selected and given the opportunity to answer the questionnaire tentative, including picking out mistakes, and adding neglected appoint which is a valid way to eliminate misinterpretations in a questionnaire [42]. The questionnaire was distributed to users on the platform (including 360DOC, Youku Video, 51ASPX, OSC (Open source China) and Douban.), who had experience creating content at least once in year 2016. Moreover, these users also need to satisfy following criteria. First, they must have contact and active on the platform, thus, the users who answer questionnaire need to contribute once at least, they cannot just scan what other users share. Second, they content is original, they cannot plagiarize from other resources online. The questionnaire was written in Chinese and send to user on social media platform via e-mail and WEBIM in 6 weeks. In the beginning, participants were informed they had the right to end the questionnaire at any time to ensure their anonymity.

\section{B. Participants}

Users of 360DOC, Youku, 51ASPX, OSC (Open source China) and Douban are invited by the instant messenger provided by the community, receiving 1350 responses in the end. As we require users complete all the questions before they can submit which is designed by the online questionnaire called SO JUMP, there is no missing value in all the responses, resulting in a final sample of 1210 valid responses. Among the 1210 questionnaire, about 287 users admit they are original user and they have contributed content at least once a year. The result of the 287 respondents show that $53 \%$ are male, $75 \%$ are below the age of 39 and $90 \%$ have college degree. Table 1 shows sample demographics in details.

\section{Instrument}

Most measurement items are obtained from previous studies to ensure validity and reliability. Table 2 shows the detailed construct items. The measurements are all assessed by using a five-point Likert scale ranging from $1=$ strongly disagree to $5=$ strongly agree. The three items except for the third for constructing lifelong learning, are adapted from Clary [43] and Yu, Jiang, \& Chan [44] add an item about contributors' overall assessment of their learning ability. The three items for user response are adapted from Wasko and Faraj [45]. Since there is no existing measurement for knowledge level, time devotion for quantity/quality, we develop the measurement.

TABLE I: CONSTRUCT ITEMS

\begin{tabular}{l|l|l}
\hline Construct & Item wording and code & Sources \\
\hline \multirow{4}{*}{$\begin{array}{l}\text { Lifelong } \\
\text { learning }\end{array}$} & I get the opportunity to exercise my & Revised based \\
& questions online & $\begin{array}{l}\bullet \text { Clary, et al. } \\
\text { I can get further understanding } \\
\text { [43] }\end{array}$ \\
& about certain topics by answering & $\bullet$ Yu, Jiang, \& \\
\hline
\end{tabular}




\begin{tabular}{|c|c|c|}
\hline & $\begin{array}{l}\text { questions online } \\
\text { - I think I can improve my learning } \\
\text { ability by sharing knowledge } \\
\text { - I can enhance my critical thinking } \\
\text { ability by answering questions online }\end{array}$ & $\begin{array}{l}\text { Chan }[44] \\
\text { - developed }\end{array}$ \\
\hline User response & $\begin{array}{l}\text { - I hope to communicate with others } \\
\text { online and offline } \\
\text { - I hope I can get feedback and } \\
\text { comments from others about my works } \\
\text { - I think I can have more friends } \\
\text { through the contact with others }\end{array}$ & $\begin{array}{l}\text { - Wasko \& } \\
\text { Faraj [45] }\end{array}$ \\
\hline Self-regulatory & $\begin{array}{l}\text { - I think the content online should } \\
\text { give priority to original } \\
\text { - I hope the resources generated by } \\
\text { myself never be inappropriate used by } \\
\text { others } \\
\text { - I think we'd better not to copy } \\
\text { others content }\end{array}$ & $\begin{array}{l}\text { - Hsu \& Lin } \\
{[15]}\end{array}$ \\
\hline $\begin{array}{l}\text { Interest and } \\
\text { curiosity }\end{array}$ & $\begin{array}{l}\text { - It brings me happy when sharing } \\
\text { content with others } \\
\text { - I am curiosity in sharing with } \\
\text { others }\end{array}$ & $\begin{array}{l}- \text { Agarwal \& } \\
\text { Karahanna [46] }\end{array}$ \\
\hline Social identity & $\begin{array}{l}\text { - I can get more attention from others } \\
\text { through generating } \\
\text { - I can win others' recognition } \\
\text { through generating } \\
\text { - I can feel the sense of belonging } \\
\text { through generating }\end{array}$ & $\begin{array}{l}\text { - Nahapiet \& } \\
\text { Ghoshal [47] }\end{array}$ \\
\hline $\begin{array}{l}\text { Behavioral } \\
\text { Intention }\end{array}$ & $\begin{array}{l}\text { - I enjoy sharing knowledge with } \\
\text { other users } \\
\text { - I enjoy helping other users by } \\
\text { sharing resources } \\
\text { - It feels nice in helping someone } \\
\text { else by uploading resources }\end{array}$ & $\begin{array}{l}\text { - Kankanhalli, } \\
\text { et al. [48] }\end{array}$ \\
\hline $\begin{array}{l}\text { User-generated } \\
\text { behavior }\end{array}$ & $\begin{array}{l}\text { - I think it is valuable to generate } \\
\text { content online } \\
\text { - In the future I will keep high } \\
\text { participation in contribution } \\
\text { - I will invite my friends to generate } \\
\text { together if I have a chance }\end{array}$ & $\begin{array}{l}\text { - Based } \\
\text { Davis [49] }\end{array}$ \\
\hline
\end{tabular}

\section{RESULT}

The first way introduced to test reliability and validity of the measuring questionnaire is confirmatory factor analysis. After testing the reliability and validity of measuring questionnaire, structural equation modeling with LISREL 8.51 was applied to give proof to research model.

\section{A. Reliability and Validity Analyses}

\begin{tabular}{l|c}
\multicolumn{2}{c}{ TABLE II: RELIABILITY TEST } \\
\hline Construct & Cronbach's $\alpha$ \\
\hline Lifelong learning & 0.795 \\
\hline User response & 0.789 \\
\hline Self-regulatory & 0.716 \\
\hline Self-efficacy & 0.810 \\
\hline Interest and curiosity & 0.738 \\
\hline Behavioral Intention & 0.728 \\
\hline User-generated behavior & 0.709 \\
\hline Total & 0.936 \\
\hline
\end{tabular}

The factor loadings, the composite and internal reliability, and the convergent and construct validity of the questionnaires were assessed. This study uses Cronbach's $\alpha$ as well as composite reliability (CR) to evaluate the consistency of the internal model with the consideration to respect to the composite reliability analysis. Cronbach's $\alpha$ reaches its threshold if it above.7. If Cronbach's $\alpha$ above .7, then the construct has reached internal consistency, see Table II . The CR of the sample results was between .702 and .936, which is exceed the essential threshold of .7. Cronbach's $\alpha$ was also bigger than .7, which suggests that the questionnaire demonstrated a certain level of reliability and that each construct measurement variable attained internal consistency.

\section{B. Test of the Structural Model}

The structural model was tested by Amos 7.0. The model-fit indices for the structural model provided evidence of a good model fit. Standardized path coefficients, path significances by each path, all supported by the path analysis results (showed in Fig. 2). Apart from the test of total model fit and the evaluation of intrinsic model quality, when explaining the model, it is necessary to understanding the correlation between the variables. First, lifelong learning $(\beta=0.19, \quad p<0.05), \quad$ user response $\quad(\beta=0.28, \quad p<0.05)$, self-efficacy $(\beta=0.35, \quad p<0.05)$, and interest and curiosity $(\beta=0.12, p<0.05)$ had positive direct effects on intention. Lifelong learning $(\beta=0.37, \mathrm{p}<0.05)$, intention $(\beta=0.32$, $p<0.05)$ and interest and curiosity $(\beta=0.14, p<0.05)$ had positive direct effects on user-generated behavior.

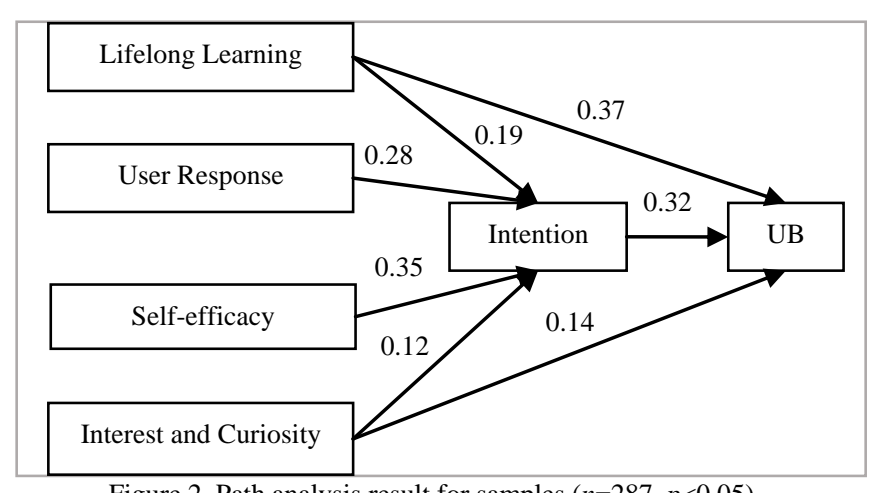

Figure 2. Path analysis result for samples $(n=287, p<0.05)$.

\section{DISCUSSION AND CONCLUSION}

The dimension of lifelong learning $(\beta=0.19, p<0.05)$, user response $(\beta=0.28, p<0.05)$, self-efficacy $(\beta=0.35, p<0.05)$, and interest and curiosity $(\beta=0.12, p<0.05)$ had positive direct effects on intention. Self-efficacy such like enjoy helping can be seen as intrinsic motivation, which has also been proved by Davis [50]. Hong proved that self-efficacy has a positive relation to learning satisfaction. Moreover, self-efficacy was also proved that has a positive relation to user generated behavior. [51] That may be most people we observed is teacher, so they may have strong desire to learn and share something. It shows that in web environment, users participate in the process of creation and sharing content is to help others, which will let the creators get great satisfaction and a sense of achievement. At the same time, we can pay attention to reward especially in the virtual network environment, such as user level, virtual currency, etc. As Poch and Martin proved that extrinsic economic rewards may improve the user's generated behavior. [52] Moreover, from the questionnaire from original users, some users admit that they hope the platform can emphasize mechanism about 
converting virtual currency for real money according to certain rules. In this research most people we investigated admit that they want economic benefit while the platform did not offer such service. The dimension of interest and curiosity has a positive effect on original users' generated behavior. The reason may be that the user can help others and cement their own knowledge system in the process of sharing knowledge. From the data of questionnaire, the undergraduate or above accounted for most of the people have a strong tendency in sharing knowledge with others. That may be the most people we observed has post degree or doctor degree, they have strong desire to help others and sharing knowledge. And the platform we choose have strong relation with education, however this thought need to be proved in the future which we cannot have a conclusion now.

The dimension of Lifelong learning $(\beta=0.37, p<0.05)$, intention $(\beta=0.32, p<0.05)$ and interest and curiosity $(\beta=0.14$, $p<0.05)$ had positive direct effects on user-generated behavior. Lifelong learning becomes a more and more important role for a person. Learners have the role of knowledge disseminator and creator, with education level improved the user also gradually realized that learning should be a continuous process, so the process of resource acquisition and creation has gradually become a habit spontaneously. As $\mathrm{Yu}$ describes in his paper that thorough answering others question, these users can search their knowledge. [53] A person learn will want to use their knowledge in their job and life, through answering others question, maybe they can hang their knowledge and have better understanding about what they obtained. But it need to point out that the self-regulatory do not have significant influence on time devotion. As Lou [54] point that learning is crucial motivation factors in knowledge contribution, so knowledge level should not become a stumbling block to stimulate creative behavior, however in our study we did not prove whether the knowledge contribution behavior has relation with knowledge level which can be proved in the future study.

Network changes life, as well as study style. Learners' learning is no longer confined to formal learning with emergence of Internet and informal learning becomes much more important. Informal learning cannot occur without the help of digital learning resources and multimedia platform lays a solid foundation for learners' diverse learning styles changing, thus affect the ways people attaining knowledge. At present, there exists a large quantity of UGC, through the survey we found that the original proportion is not high, the user creation enthusiasm is still need to strengthen.

\section{REFERENCES}

[1] D. Gasevic et al., "Where is research on massive open online courses headed? A data analysis of the MOOC research initiative," The International Review of Research in Open and Distributed Learning, vol. 15 , no. $5,2014$.

[2] OECD. (2013). Education at a glance 2013: OECD indicators. [Online] Available:

http://www.oecd.org/edu/eag2013\%20\%28eng\%29eFINAL $\% 2020 \% 2$ 0June\%202013.pdf

[3] M. Asselin et al., "Learning from YouTube: An analysis of information literacy in user discourse," in Proc. the 2011 iConference, pp. 640-642, 2011.
[4] R. Stoeckl et al., "Motivations to produce user generated content: Differences between webloggers and videobloggers," BLED 2007 Proceedings, vol. 30, 2007.

[5] S. Bowman and C. Willis, We Media: How Audiences Are Shaping the Future of News and Information, 2003.

[6] W. Schweiger and O. Quiring, User-Generated Content auf massenmedialen Websites-eine Spielart der Interaktivität oder etwas völlig anderes. Neue Technik, nеuе Medien, neue Gesellschaft, pp. 87-109, 2006.

[7] CNNIC. (2016). Statistical report: Internet network development state of China. [Online]. Available: https://cnnic.cn/gywm/xwzx/rdxw/2015/201601/W020160122639198 410766.pdf

[8] J. Nielsen, Participation inequality: lurkers vs. contributors in Internet communities. [Online]. Available: http://www.useit.com/alertbox/Participationinequalitv.html

[9] X. Yang et al., "Student-generated content in college teaching: Content quality, behavioural pattern and learning performance," Journal of Computer Assisted Learning, vol. 32, no. 1, pp. 1-15, 2016.

[10] S. Paavola and K. Hakkarainen, "The knowledge creation metaphor-An emergent epistemological approach to learning," Science and Education, vol. 14, no. 6, pp. 535-557, 2005.

[11] H. L. Yang and C. Y. Lai, "Motivations of Wikipedia content contributors," Computers in Human Behavior, vol. 26, no. 6, pp. 1377-1383, 2010.

[12] A. Doan et al., "Crowdsourcing systems on the world-wide web," Communications of the ACM, vol. 54, no. 4, pp. 86-96, 2011.

[13] P. Fichman, "A comparative assessment of answer quality on four question answering sites," Journal of Information Science, vol. 37, no. 5, pp. 476-486, 2011.

[14] K. Newton and M. J. Riggs, "Everybody's talking but who's listening? Hearing the user's voice above the noise, with content strategy and design thinking," 2016.

[15] K. Y. Lin and H. P. Lu, "Why people use social networking sites: An empirical study integrating network externalities and motivation theory," Computers in Human Behavior, vol. 27, no. 3, pp. 1152-1161, 2011.

[16] J. W. Atkinson and D. Birch, "The dynamics of achievement-oriented activity," Motivation and Achievement, vol. 271, p. 325, 1974.

[17] E. L. Deci, Intrinsic Motivation, New York: Plenum Press, 1975.

[18] F. D. Davis et al., "Extrinsic and intrinsic motivation to use computers in the workplace," Journal of Applied Social Psychology, vol. 22, pp. $1111-1132,1992$.

[19] E. Kim and B. Lee, "An economic analysis of customer selection and leveraging strategies in a market where network externalities exist," Decision Support Systems, vol. 44, pp. 124-134, 2007.

[20] R. F. Baumeister, "Toward a general theory of motivation: Problems, challenges, opportunities, and the big picture," Motivation and Emotion, vol. 40, no. 1, pp. 1-10, 2016.

[21] R. Cropanzano and M. S. Mitchell, "Social exchange theory: An interdisciplinary review," Journal of management, vol. 31, no. 6, pp. 874-900, 2005.

[22] M. Uhl-Bien and J. M. Maslyn, "Reciprocity in manager-subordinate relationships: Components, configurations, and outcomes," Journal of Management, vol. 29, no. 4, pp. 511-532, 2003.

[23] A. W. Gouldner, "The norm of reciprocity: A preliminary statement," American Sociological Review, pp. 161-178, 1960.

[24] S. W. Chou and C. S. Hsu, "Understanding online repurchase intention: social exchange theory and shopping habit," Information Systems and e-Business Management, vol. 14, no. 1, pp. 19-45, 2016.

[25] M. Bong and E. M. Skaalvik, "Academic self-concept and self-efficacy: How different are they really?" Educational Psychology Review, vol. 15 , no. 1, pp. 1-40, 2003

[26] E. M. Skaalvik, "Self-enhancing and self-defeating ego orientation: Relations with task and avoidance orientation, achievement, self-perceptions, and anxiety," Journal of Educational Psychology, vol. 89, no. 1, p. 71, 1997.

[27] A. Bandura, "Adolescent development from an agentic perspective," Self-efficacy Beliefs of Adolescents, vol. 5, no. 1-43, 2006.

[28] M. Tower et al., "Social networking as a learning tool: Nursing students' perception of efficacy," Nurse Education Today, vol. 34, no. 6, pp. 1012-1017, 2014.

[29] J. C. Hong et al., "Internet cognitive failure relevant to self-efficacy, learning interest, and satisfaction with social media learning," Computers in Human Behavior, vol. 55, pp. 214-222, 2016.

[30] A. Bandura, "Adolescent development from an agentic perspective," Self-efficacy Beliefs of Adolescents, vol. 5, no. 1-43, 2006. 
[31] A. Susarla et al., "Social networks and the diffusion of user-generated content: Evidence from YouTube," Information Systems Research, vol. 23, no. 1, pp. 23-41, 2012.

[32] F. Y. Wang et al., "Social computing: From social informatics to social intelligence," IEEE Intelligent Systems, vol. 22, no. 2, pp. 79-83, 2007.

[33] R. Poch and B. Martin, "Effects of intrinsic and extrinsic motivation on user-generated content," Journal of Strategic Marketing, vol. 23, no. 4, pp. 305-317, 2015.

[34] J. Knoll and R. Proksch, "Why we watch others' responses to online advertising-investigating users' motivations for viewing user-generated content in the context of online advertising," Journal of Marketing Communications, pp. 1-13, 2015.

[35] J. Lou et al., "Drivers of knowledge contribution quality and quantity in online question and answering communities," 2011.

[36] J. Yu et al., "The influence of sociotechnological mechanisms on individual motivation toward knowledge contribution in problem-solving virtual communities," IEEE Transactions on Professional Communication, vol. 54, no. 2, pp. 152-167, 2011.

[37] D. Boud et al., "Peer learning in higher education: Learning from and with each other," Routledge, 2014.

[38] R. M. Ryan et al., "Relation of reward contingency and interpersonal context to intrinsic motivation: A review and test using cognitive evaluation theory," Journal of personality and Social Psychology, vol. 45 , no. 4, p. 736, 1983.

[39] M. Tower et al., "Social networking as a learning tool: Nursing students' perception of efficacy," Nurse Education Today, vol. 34, no. 6 , pp. 1012-1017, 2014

[40] E. L. Deci and R. M. Ryan, Intrinsic Motivation and Self-determination in Human Behavior, New York and London: Plenum, 1985.

[41] A. Aldao et al., "Emotion-regulation strategies across psychopathology: A meta-analytic review," Clinical Psychology Review, vol. 30, no. 2, pp. 217-237, 2010.

[42] O. Karnieli-Miller et al., "Power relations in qualitative research," Qualitative Health Research, vol. 19, no. 2, pp. 279-289, 2009.

[43] E. G. Clary et al., "Understanding and assessing the motivations of volunteers: a functional approach," Journal of Personality and Social Psychology, vol. 74, no. 6, p. 1516, 1998.

[44] J. Yu et al., "The influence of sociotechnological mechanisms on individual motivation toward knowledge contribution in problem-solving virtual communities," IEEE Transactions on Professional Communication, vol. 54, no. 2, pp. 152-167, 2011.

[45] M. M. Wasko and S. Faraj, "It is what one does": why people participate and help others in electronic communities of practice," The Journal of Strategic Information Systems, vol. 9, no. 2, pp. 155-173, 2000.

[46] R. Agarwal and E. Karahanna, "Time flies when you're having fun: Cognitive absorption and beliefs about information technology usage," MIS Quarterly, pp. 665-694, 2000.

[47] J. Nahapiet and S. Ghoshal, "Social capital, intellectual capital, and the organizational advantage," Academy of Management Review, vol. 23 , no. 2, pp. 242-266, 1998.

[48] O. Karnieli-Miller et al., "Power relations in qualitative research," Qualitative Health Research, vol. 19, no. 2, pp. 279-289, 2009.

[49] F. D. Davis, "Perceived usefulness, perceived ease of use, and user acceptance of information technology," MIS Quarterly, pp. 319-340, 1989.

[50] F. D. Davis et al., "Extrinsic and intrinsic motivation to use computers in the workplace," Journal of Applied Social Psychology, vol. 22, pp. 1111-1132, 1992.

[51] J. C. Hong et al., "Internet cognitive failure relevant to self-efficacy, learning interest, and satisfaction with social media learning," Computers in Human Behavior, vol. 55, pp. 214-222, 2016.

[52] R. Poch and B. Martin, "Effects of intrinsic and extrinsic motivation on user-generated content," Journal of Strategic Marketing, vol. 23, no. 4, pp. 305-317, 2015.
[53] J. Yu et al., "The influence of sociotechnological mechanisms on individual motivation toward knowledge contribution in problem-solving virtual communities," IEEE Transactions on Professional Communication, vol. 54, no. 2, pp. 152-167, 2011.

[54] J. Lou et al., "Drivers of knowledge contribution quality and quantity in online question and answering communities," 2011.

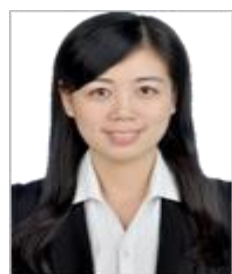

Jing Du was born in Hubei province, China in March, 1989. She obtained her master degree at Central China Normal University in 2015 which located in Wuhan city, China.

Her major is educational Technology, and during her master period she interested in online resources design and development.

Since 2015, she becomes a doctoral candidate in Beijing Normal University and is interested in learning space design, computer supported collaborative learning and intelligent tutoring system.

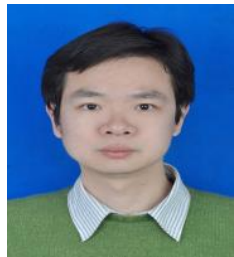

Liyong Wan was born in Hubei province, China in December, 1980. She obtained his doctor degree at Central China Normal University in 2013 which located in Wuhan city, China.

$\mathrm{He}$ currently works as a vice professor in South-Central University For Nationalities .His major is educational Technology. His research direction includes the development of education informatization, Open educational resources and the educational technology ability of students. He has accomplished 5 research projects and published more than 40 research papers.

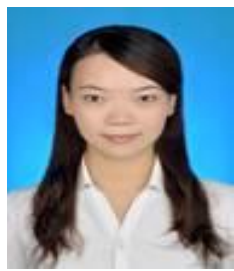

Jingjing Xu was born in Shanxi province, China in April 1987. She obtained her master degree at Central China Normal University in 2015 which located in Wuhan city, China.

Her major is education Technology, and mainly research the design and development of education information resources. In the master's stage, she was the ASSISTANT for the public compulsory course of modern education technology from September 2013 to June 2014. And now she is the Doctoral Candidate of Educational Technology. She is the ASSISTANT for the public compulsory course of introduction to education technology from September 2016 to January 2017.

Her research direction includes the Knowledge Science and Knowledge Engineering, ICT in education, smart learning, etc.

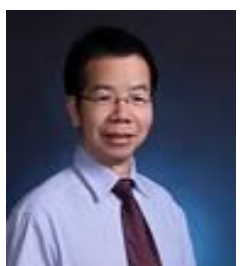

Ronghuai Huang was born in Hunan province, China in February, 1965. He is the PH.D. Supervisor and professor of Beijing Normal University.

He currently works as the Co-Dean of Beijing Normal University Smart Learning Institute, Deputy Director of Collaborative and Innovative Center for Educational Technology, Director of Digital Learning and Public Education Service Engineering Research Center, Director of Beijing Key Laboratory for Educational Technology.

$\mathrm{He}$ also works part-timely as Vice President of the Teaching Guidance Committee for Educational Technology, Member of The Ministry of ICT in education Expert Panel, Vice President of China Association for Educational Technology (CAET), President of the International Association of Smart Learning Environment (IASLE) and so forth. His research direction includes the development of international education informatization, strategy on education informatization that drives school modernization, standard revision of ICT courses offered by senior middle schools and so forth. He has accomplished more than 70 research projects. 